This item was submitted to Loughborough's Research Repository by the author.

Items in Figshare are protected by copyright, with all rights reserved, unless otherwise indicated.

\title{
Chronic obstructive pulmonary disease (COPD), illness narratives and Elias's sociology of knowledge
}

PLEASE CITE THE PUBLISHED VERSION

https://doi.org/10.1016/j.socscimed.2017.09.022

\section{PUBLISHER}

(C) Elsevier

\section{VERSION}

AM (Accepted Manuscript)

\section{PUBLISHER STATEMENT}

This work is made available according to the conditions of the Creative Commons Attribution-NonCommercialNoDerivatives 4.0 International (CC BY-NC-ND 4.0) licence. Full details of this licence are available at: https://creativecommons.org/licenses/by-nc-nd/4.0/

\section{LICENCE}

CC BY-NC-ND 4.0

\section{REPOSITORY RECORD}

Malcolm, Dominic, Mark W. Orme, Mike Morgan, and Lauren Sherar. 2017. "Chronic Obstructive Pulmonary Disease (COPD), IIIness Narratives and Elias's Sociology of Knowledge”. Loughborough University. https://hdl.handle.net/2134/26790. 


\section{Abstract}

4 This paper draws on Elias's sociology of knowledge to provide a critical assessment of illness

5 narratives. Focusing on a cohort of chronic obstructive pulmonary disease (COPD) patients

$6 \quad(n=26)$, the paper employs a comparative analysis of mixed method data derived from

7 qualitative interviews, quantitative questionnaires, and physiological and accelerometer

8 testing. The article firstly compares four narratives conveyed in interviews with the broader

9 paradigmatic approach to illness narratives and existing COPD-specific studies. It then

10 explores the relationship between these ‘stories' and COPD patients’ biographical

11 contingencies (e.g. age, wealth, context of diagnosis) and embodied condition (e.g. co-

12 morbidities, lung function), demonstrating how illness narratives are shaped by both broader

13 social structural factors and embodied experience. Invoking Elias we further find that

14 different narrative subthemes are varyingly affected by patients' emotional engagement and

15 ontological security and thus that people are differently enabled or constrained to present

16 illness narratives that are consistent with their broader social and physical condition.

17 Consequently, while narratives, social structure and embodied experience are interdependent, 18 our reading of 'truth' must be sensitive to the social positioning of the 'teller' and the specific

19 content being relayed. The paper therefore presents a more systematic, comparative, bio-

20 psycho-social analysis than has hitherto been produced.

21 Keywords

22 UK; Illness narratives; COPD; Elias; Emotions; Bio-psycho-social approach 


\section{Introduction}

25 Chronic obstructive pulmonary disease (COPD) is characterised by airflow obstruction which 26 is progressive and cannot be fully reversed. Diagnosis normally occurs post-40 years of age, 27 and is therefore also often associated with multiple co-morbidities. Frequently caused by 28 tobacco inhalation, COPD disproportionately affects males from lower socio-economic 29 groups (Hansen et al. 2007), but is predicted to be the fourth leading cause of global mortality, morbidity and disability by 2030 (Boeckxstaens et al. 2012).

Primary physical symptoms include breathlessness (dyspnoea), chronic cough and sputum production (Williams et al. 2011). Common measures of breathlessness and other symptoms include the modified Medical Research Council (mMRC) dyspnoea scale (Bestall 1988) and the COPD Assessment Test (CAT) (Jones 2009) questionnaire. Additionally, physical measures such as lung function tests (e.g. spirometry), field walking assessments (e.g. incremental shuttle walk test (ISWT)) and more recently physical activity (e.g. using an accelerometer to measure bodily movement) are used to provide a more complete picture of the heterogeneity of the impact of the disease.

Treatment for COPD focuses on smoking cessation, inhaler medication and pulmonary rehabilitation (Hansen et al. 2007). The health benefits of physical exercise for

41 COPD patients include reduced breathlessness, improved muscle strength, and improved 42 management of exacerbation, which potentially lead to extended life expectancy, enhanced 43 life quality and reduced healthcare usage (Williams 2011). However, the symptoms of COPD 44 tend to create a double-bind situation (Elias 1987a) in which such sedentary lifestyles lead to deconditioning, muscle weakness, further reductions in physical activity, and therefore more severe symptoms (Polkey 2006). 

and patients' everyday experiences. While psychological studies foreground smoking in patients' accounts of causation and the consequent guilt of having a 'self-inflicted disease'

50 (Lindqvist and Halberg 2010: 460), sociological research explores patients' multi-causal 51 models combining smoking with industrial/environmental factors and family histories 52 (Hansen et al. 2007; Bailey et al. 2009). By explaining causation according to factors beyond their control, COPD patients mitigate the moral implications of appearing to have a lifestyleinduced illness. Second, the everyday experiences of COPD patients have been depicted as entailing five managing strategies: making sense of existence; adjusting to bodily restrictions; making excuses for smoking related cause; surrendering to fate; and creating compliance 57 with daily medication (Lindqvist and Hallberg 2010: 462). Others have highlighted patients’ lowered self-esteem and depressive tendencies (Nicholson and Anderson 2003; Williams 1993), and condition-specific features such as the relationship between anxiety and acute exacerbations (Bailey 2001).

As useful as these studies are, they exhibit four particular limitations. First, while most employ a variant of narrative analysis, the frequent reliance on grounded theory means that few studies locate their findings relative to a broader corpus of illness narrative work.

64 Second, many studies explicitly exclude participants with co-morbidities or at least disregard 65 other physical ailments and thus present de-contextualised or disembodied accounts of illness. Third, this work largely ignores the influence of broader social structural factors. Fourth, the emphasis on smoking militates against the consideration of other aspects of treatments, and in particular the imperatives of remaining physically active. patient experiences that explicitly relates to broader analyses of illness narratives. It 71 subsequently provides a critical reading of illness narratives through the exploration of their 
72 interdependence with both biographical contingencies (e.g. age, wealth) and embodied 73 condition (e.g. co-morbidities, lung function). Finally it seeks to explain these relationships

74 by considering the role of agency in the process of socially constructing knowledge. The 75 outcome is a more systematic, comparative and, to a degree, bio-psycho-social analysis than 76 has hitherto been produced. In pursuing our central research question - how do social, 77 physical and interactional factors influence the illness narratives patients present? - we first consider debates regarding illness narratives and the premises of Elias's sociology of 79 knowledge.

\section{Illness narratives}

Concern with illness narratives is predicated on the understanding that disease entails both physiological disturbance and biographical disruption (Bury 1982). The value of the approach is to illustrate how the practical consequences and symbolic significance of illness shape how people see themselves, how they think others see them and, ultimately, the overall experience and impact of disease. Illness narratives help to establish a sense of meaning or purpose which helps relocate the relationship between the self and world. They do not simply reflect, but create and structure symptoms/suffering, and are themselves shaped by broader social, cultural and material contingencies. Key principles of this approach are that the narrative strategies available to individuals are influenced by their life experience and social location, and that the narrative we produce effectively becomes the illness experience. It is important, however, to recognise the fluidity of 'identity construction [which] is a continuous, evolving dual directional process’' (Yoshida 1993: 241). 
symptoms, and its immediate or "proximate” effects on the body, self and others' (Bury 2001: 268). Contingent narratives are therefore central to the focus on everyday experiences of COPD patients in relation to everyday management strategies and dealing with extreme exacerbations (Bailey 2001; Williams et al. 2007). Moral narratives reveal the broader social context in which illness is experienced. They contain an evaluative dimension to the personal and social condition, potentially combining themes of culpability and exoneration and thus 'help to maintain self worth’ (Bury 2001: 275). Moral narratives are therefore central to the focus on the aetiological role of smoking prominent in qualitative studies of COPD 104 (Nicholson and Anderson 2003; Lindqvist and Halberg 2010). Finally core narratives may be epic or tragic, depicting the illness experience as progressive, regressive or stable. The core narrative depicted in existing COPD studies is therefore largely tragic, with portrayals of stability or slow decline (Williams et al. 2011), and analysis of acute exacerbations depicting dramatic if intermittent regression (Bailey 2001).

Frank’s (1995) widely used and highly regarded typology identifies three primary

110 illness narratives: chaos, quest and restitution. A single story/interview can contain elements 111 of all three, but it is likely that one will predominate. If the dominant narrative is chaos, a 112 person will portray a sense of being out of control, struggling to understand what is 113 happening to them, and frequently reporting unexplained symptoms and clinical and/or social 114 rejection. In a predominantly quest narrative, illness is interpreted as a challenge to be 115 confronted, an impetus for change or as having a broader purpose. Finally, restitution 116 narratives are based on assumptions that, while medicine will return the body to its former 117 self, it is behoven on the sufferer to resolve illness. The restitution narrative is both the expected and dominant illness narrative in Western cultures, particularly common amongst 119 the recently ill who perceive themselves as temporarily in an 'unlucky' state. 
121 by necessity, is derived from the 'special occasion' of being interviewed; and b) the lack of 122 attention to social structure (Riessman 2002). Atkinson (2009), for instance, argues that the 123 illness narrative approach stems from broader socio-historical processes which valorise 'the 124 interview' in the contemporary cultural condition. In assessing the meaning and function of 125 including multiple narrative genres within an account of illness, Jordens et al. (2001: 1235) conclude that while 'generic complexity of the illness narratives was an index of the degree

127 of life disruption experienced', the form of narrative is also shaped by the unfolding of 128 interaction. Simple narratives are presented by those who have reinstated order post-diagnosis, 129 and complex and chaotic narratives are constructed in the 'real time' of the interview. The 130 narrative approach further entails an a priori commitment to the value of patients' experiential self-knowledge relative to clinicians’ impersonal biomedical knowledge, to subjective satisfaction rather than health outcomes (Timmermans and Haas 2008). It thus treats patient accounts uncritically, positioning them as testimony rather than perspective. In 134 so doing, we frequently see a psychologisation and de-socialisation of the individual, not only 135 obscuring the ways in which the illness experience is contoured by social location, but missing the 'dynamic interplay between biological health and social life' (Timmermans and

137 Haas 2008: 661). Responses to these issues include calls for more 'systematic, comparative 138 analysis' (Atkinson 2009: 2.1) and a move towards a sociology of disease (Timmermans and 139 Haas 2008).

Reviewing debates over the use of illness narrative, Thomas (2010) highlights the 141 clash of poststructural and 'traditional sociological' methodologies. The former emphasises 142 reflexivity, emotion, empathy and ethical/political action, while the latter is depicted as 143 positivistic, treating 'illness narratives as social facts to be interpreted' (Thomas 2010: 655). 144 Thomas concludes that one's position in this debate derives from a number of fundamental 
145 sociological questions: the relationship between micro- and macro-sociology, subjective vs

146 objective epistemologies, the role of values in sociological research and how to demonstrate

147 social scientific methodological rigour. Thomas comes to an essentially post-dualist position

148 which reconceptualises these questions from an either/or into consideration of the potential

149 balance of the two extremes of each respective spectrum. While Thomas' position is neither 150 explicitly nor implicitly informed by Eliasian sociology, it is essentially compatible with key 151 aspects of the approach outlined below.

\section{Illness Narratives and Eliasian Sociology}

Elias’s central theory, The Civilizing Process (2000), undertakes an 'analysis of the historical development of emotions and psychological life ... in relation to the connections ... with larger scale processes such as state formation, urbanisation and economic development’

157 (van Krieken 1998: 353). Fundamental to this project, therefore, is an attempt to explain 158 micro-sociological changes in relation to macro-, social structural developments (and viceversa). Indeed, The Civilizing Process centrally explores the interrelationship between particular social conditions and habitual ways of thinking and acting. Identities are thus dynamic but their rate of change varies according to broader social structural influences. Elias 162 (1987b) further depicts humans (in their physical, existential, cognitive, and affective 163 dimensions) as inherently situated in a recursive relationship between the biological and the social, illustrating a commitment to engage directly with the radical interdependence of embodied experiences and social processes.

Elias's sociology of knowledge is similarly informed by post-dualist principles.

167 Specifically, Elias rejected the dichotomy of 'truth' and social construction/falsehood by 168 emphasising that knowledge cannot be divorced from its social and processual character. 
169 Consequently Elias focussed on the historical and contextual specificity of the blend of 170 involvement (self-interest, emotion, etc.) and detachment (distanciation, reflexivity, etc.)

171 which characterises all human knowledge. For example, the shift from an oral to written

172 transmission of knowledge enables the development and dissemination of more complex

173 concepts. While this relationship is not a 'zero-sum' game where, e.g., detachment 174 necessarily increases as involvement decreases (Kilminster 2004), generally speaking, 175 contemporary western modes of thought are marked by the re-/displacement of 'magical176 mythical' or 'fantasy-laden' thinking which is 'highly influenced by immediate interests and 177 strong emotions' (Wilterdink 2003: 303), with relatively detached, rational, reflexive forms 178 of scientific knowledge (Elias 1987a). The co-existence of traditional medicine and 179 biomedicalisation in the treatment of elite sport injury is an apposite example (Faulkner et al. 180 2017). For Elias, detachment not only entails thinking about oneself as a social being rather 181 than an individual with biological urges, but may entail thinking about the process of 182 producing knowledge, e.g. while being interviewed (Kilminster 2004). Conditions of relative 183 physical and social insecurity (during times of war, but equally when one becomes ill) fuel 184 more involved thought processes. Crucially, however, the primary determinate of what 185 survives as 'knowledge' is social; namely, those concepts and ideas which survive 'reality testing ... in the crucible of experience' (Elias 1987a: 56). For Elias, part of that reality 187 testing is the emotional impact of holding particular ideas. Accordingly, rejecting smoking as 188 the cause of COPD may be emotionally comforting and thus held to be 'true'. The value of drawing on Elias's sociological approach, therefore, is that it sensitises 190 us to an analysis of illness narratives that focuses on the way accounts relate to both agency 191 and structure, the embodied and social experience. Our aim is not, primarily, to assess the 192 authenticity of narrative accounts but to illustrate the contingencies upon which more or less 193 'reality congruent' accounts prevail including, for instance, consideration of both the social 
and emotional consequences of expressing particular illness narratives. We find that people are differently enabled or constrained to present illness narratives that are consistent with their broader social and physical condition, and different narrative subthemes are more-or-

197 less affected by patients' emotional engagement.

\section{Method}

COPD patients were recruited as part of the Physical Activity and Respiratory Health (PhARaoH) Study which was granted ethical approval by National Health Service Research Ethics Committee East Midlands-Nottingham 2 (see Orme et al. 2016 for further details). General Practitioners (GPs) identified eligible participants from patient records (those with a diagnosis of COPD, and aged 40 to 75 years to be in line with comparable studies, e.g. Vestbo et al. 2008), and sent them study information and enrolment materials. One hundred and thirty-nine COPD patients plus a control group (recruited using various media, $\mathrm{n}=297$ ) subsequently participated in the clinically-based quantitative phase of the research, consisting of: providing informed consent, responding to questionnaires covering demographics, smoking history, perceptions of health; participating in physical measurements (blood 210 pressure, spirometry, skeletal muscle strength, ISWT) and a 7-day accelerometer 211 measurement of physical activity.

The qualitative phase of the study used a maximum variation sampling technique to 213 generate a sub-sample representative of the illness spectrum (using CAT and mMRC scores). 214 Thirty-four of the 139 COPD patients were initially contacted, supplied with a participant 215 information sheet for this second study phase and given at least 24 hours to consider their 216 inclusion. Eight did not respond or did not consent to being interviewed. In total 26 217 interviews were conducted, comprising 18 males and 8 females. All participants self- 
218 identified as 'white' (British or Irish). Socio-demographic characteristics of the sample 219 appear in Table 1.

Interviews lasting 30-55 minutes took place in participants' homes, hospital and

221 university facilities, or other convenient places (e.g. cafes). Main themes included biography

222 (as a COPD patient), current impact on daily living and physical activity, and barriers and

223 enablers to being physically active. Data saturation was thought to have been achieved after

22423 interviews and confirmed after three further, already scheduled, interviews were

225 conducted. Each was digitally recorded and professionally transcribed as soon as possible

226 after the interview concluded. Interviews were conducted by the (male) lead qualitative 227 researcher $(\mathrm{n}=19)$ and a (female) research nurse $(\mathrm{n}=7)$ trained in qualitative research methods 228 and inducted into the study by the lead qualitative researcher.

Thematic analysis was an iterative process which began in discussions between the 230 two interviewers as transcripts were returned. Analysis became more intensive once all 231 interviews had been completed. Specifically, the lead qualitative researcher repeatedly read 232 the transcripts and coded data based on existing literature and the repetition of particular 233 types of phrases and narrative themes. This initial coding was subject to a systematic 234 comparative approach, identifying differences and commonalites across the transcripts, and 235 developing overarching themes. To preserve anonymity identifier codes used in the broader study (MP and FP signify male and female participant respectively, while the number represents sequential enrolment) are used to report transcript excerpts. As the four core narratives presented here crystalised - Chaos, Challenge, Contrary and Coping - a secondary 239 phase of analysis began, exploring patients’ narratives in relation to quantitatively recorded 240 material factors (e.g. demographics, education, income), physiological measures (e.g. 
241 strength, lung function, physical activity) and behavioural perceptions (expressed via 242 questionnaire).

A fundamental issue with this mixed-method approach is the relative evaluation of the

244 qualitative and quantitative data. Following Elias, we interpret neither as operating a 245 monopoly over 'truth'. Following Atkinson (2009) we do not seek to valorise the interview.

246 Rather both must be reflexively considered with higher levels of detachment (Elias 1987a), or 247 'managed prejudice' (Thomas 2010), to produce the most 'reality-congruent' understanding. 248 The order in which the findings are presented relates more to the analytic journey undertaken 249 than it does to a view that the former should be 'checked' according to the latter. While 250 cognisant of the view that qualitative data are predicated on the belief that what is important 251 is the 'meaning of what is said rather than the generalizability to make comparisons' 252 (Nicholson and Anderson 2003: 255), the post-dualist, bio-psycho-social, Eliasian position commends an exploration of the interdependence of the different forms of data.

\section{COPD Patients’ Illness Narratives}

Six interviewees presented a primary narrative of Chaos. This theme contained strong similarities with the managing strategy Lindqvist and Hallberg (2010) called Surrendering to fate. The 'chaos' reported could be directly (e.g. difficulty breathing, cessation of work, weight gain) or indirectly (e.g. caring for others, co-morbidities) linked to COPD. These essentially tragic core narratives (Bury 2001) detailed how COPD had a major impact on daily living with interviewees describing themselves as 'destroyed' (MP392), lower than 'a second class citizen' (MP019), or being 'stuck in a vicious circle' (FP018). The inability to control or manage their condition included following recommendations to stop smoking

264 which one interviewee described as 'the worst thing I've done because I kept putting on 
weight' (FP147). Of all four groups, those presenting a chaos narrative found the initial diagnosis of COPD particularly biographically disruptive. One interviewee described how on visiting his GP he was sent directly to hospital, directed to stop work, and subsequently experienced panic attacks and depression (MP019). However, in contrast to feelings of guilt through perceived self-infliction (Lindqvist and Hallberg 2010) and/or of being socially

270 burdensome, the central moral narrative focussed on beliefs that having COPD was in some 271 sense unfair or undeserved; '[it] makes me so angry ... I’ve never been overweight, always 272 had a good diet, always been physically active’ (FP023). Many expressed a lack of social 273 support, little empathy from those who treated them 'like a child' (MP019), and being 274 socially isolated because ‘I don’t go out much’ (MP462). Episodes of severe breathlessness 275 (defined by the respondents' depiction of panic and/or subsequent hospitalisation) were not 276 particularly common in this cohort, but in being very conscious that 'it's an untreatable 277 disease' (FP147), a sense of regression was. All believed that increased physical activity 278 would have health benefits, but none saw themselves as able to adopt routine structured 279 exercise. Paralleling Frank’s (1995) chaos narrative category, most reported conflict with 280 healthcare professionals; 'They don’t call you in, they don’t do anything ... I've got plenty of counterarguments for what they're saying ... I've got no faith in them [GPs]' (MP462).

Five expressed the desire to counter or Challenge their condition through lifestyle modification. Reminiscent of Lindqvist and Hallberg's (2010) Making sense of existence, 284 they described their initial COPD diagnosis as only mildly biographically disruptive - a 285 'shock to me ... but to be honest I wasn’t worried' (MP304) - sufficient to induce lifestyle 286 change but controllably. Contingent narratives illustrated significant impact on daily living, 287 yet individuals frequently used terms such as 'in control' (MP483), 'mind over matter' 288 (FP382) or '[I] learned to deal with it ... you adapt' (MP192), to characterise their ability to 289 self-manage. The cohort reported supportive social networks. None reported their condition 
290 to be significantly worsening. All described being positively disposed towards physical 291 activity, citing cycling, dancing, football, gym and gardening as they strove to retain a normal 292 life; 'I looked at it and thought, well you've got two ways to go. You can feel sorry for 293 yourself and give in or you keep carrying on, which is what I've done' (FP382). Individuals 294 rarely foregrounded the role of medicine or medical personnel despite reporting some of the 295 more severe experiences of breathlessness and episodes of hospitalisation. By implication, 296 therefore, this group portrayed a sense that they had overcome their problems through active 297 and judicious self-management, refusing 'to take a back seat .... push[ing] my body as far as 298 it will go' (MP304). The heroism in this epic narrative appeared as interviewees contrasted 299 themselves with those 'people my age [who] look 92 because they sit down and they give up 300 don't they' (FP050). Aligned with elements of progression, purpose and impetus for change, 301 the Challenge group closely aligns with Frank’s (1995) quest narrative.

The final two groups were labelled Contrary and Coping. While the former exhibited elements of Lindqvist and Hallberg's (2010) Making excuses for smoking-related cause, the latter resembled the managing strategy of Adjusting to bodily restriction. Both essentially represented what Frank (1995) described as a restitution narrative. While condition-specific factors - guilt of self-infliction, knowledge that 'recovery' COPD was impossible - combined 307 to limit the degree of restitution anticipated, the moral narratives of the contrary and coping 308 groups centrally positioned the teller as fulfilling the social expectations of resolving their condition. Frank (1995) suggests the restitution narrative tends to be dominant and, together, 310 these two groups constituted almost $60 \%(n=15)$ of the sample. those presenting a contrary narrative expressed the least biographical disruption in relation to 
314 initial diagnosis, and many continued to exhibit denial, attributing symptoms to 'the ageing process' (MP176), suggesting that 'it was perhaps a misdiagnosis ... I don’t believe it'

316 (FP275), or revealing that 'I almost feel a bit of a fraud' (MP437). They thus suggested that

317 COPD did not directly define their identity or significantly structure their lives, typically

318 stating that 'I don't worry about it' because compared to others 'I think [to myself] “Oh God, 319 you've got nothing”' (FP166). Another claimed 'I don't care, I was told I'd be dead by 21' 320 (MP160). All defined their respiratory health as stable or improving, portrayed an ability to exert considerable control over their condition - 'it’s an attitude isn't it' (MP176) - and expressed little concern about future deterioration. While the degree of socially supportive 323 relations varied, none portrayed a sense of isolation. Although two currently exercised 324 explicitly to enhance health, most viewed physical activity as the Making excuses cohort viewed smoking; acknowledging the potential benefits but expressing rationales ranging from control - 'I'm going to do what I can do' (MP160) - to indifference - 'I can’t be bothered'

327 (MP437). Most downplayed the significance of healthcare, either expressing 'hope' that 328 medication worked (MP187) or the belief that an 'inhaler helps a litte bit but not that much' 329 (MP160). None recalled experiencing severe episodes of dyspnea or conflicts with healthcare 330 professionals.

The seven interviewees who expressed a Coping narrative represented a moderated 332 form of the contrary groups' heroic narrative. While both groups expressed limited 333 biographical disruption on initial diagnosis, and satisfaction at their control of the condition, 334 the central distinction was that the contingent narrative of the coping cohort depicted greater 335 limitations in daily living. Within the Coping cohort, interviewees recalled being 'out of 336 breadth and [I] couldn’t cope with the job I was doing’ (MP009), struggling with routine 337 domestic work, such as cleaning (MP302) and carrying grandchildren (MP465), and relying 338 on family or paid domestic help (MP345, FP476). While some were conscious that their 
339 condition was deteriorating, the decline was perceived to be manageable, one interviewee 340 stating, 'I know that progression is going to be that I will virtually become inactive physically.

341 I know that and I'm prepared for that, but at the moment I'm just managing to cope' (MP345).

342 Respondents mainly reported good social networks and supportive partners. Most reported a

343 strong history of physical activity participation although motivation for their continued 344 exercising ranged from the pleasurable - 'it hurts when I do it [play golf] but I really enjoy it' 345 (MP125) - to the instrumental - 'it's not about enjoyment, it's about keeping fit' (FP476). 346 However, akin to Lindqvist and Hallberg's (2010) Adjusting to bodily restriction 347 interviewees who emphasised saving energy, not hurrying, and being responsive to bodily 348 sensations, a particularly notable feature was how many specifically used the term 'own pace' 349 to describe attitudes to physical activity (MP009, MP125, MP345, MP465). None spoke of 350 their relations with healthcare providers, although four of the seven had experienced severe 351 episodes of dyspnoea.

Interviewees, therefore, expressed illness narratives which largely resonated with the 353 broader paradigmatic approach (Frank 1995), and Lindqvist and Hallberg's (2010) earlier 354 study of COPD patients (see Supplementary Files for extracts from interviews with 355 individuals in each narrative group). But as behoven by a more bio-psycho-social, Eliasian 356 approach, we subsequently assessed the resonance between narratives and: a) broader social structural factors; and b) embodied conditions. Through this we were able to consider 358 interviewees' accounts within a broader context of their lived reality and thus begin to reflect 359 on how particular illness narratives emerge.

\section{Illness narratives and quantitative measures}


364 findings. The chaos narrative, in which multiple conditions and complications merged into pronounced biographical disruption, was most commonly presented by female interviewees, while the coping and contrary narratives downplaying or refuting the condition was most

367 frequently expressed by male respondents (see Table 1). Similarly more extreme biographical 368 disruption was commonly expressed by younger and more recently diagnosed interviewees. 369 While mean ages were not particularly different, the chaos cohort contained the largest proportion of people in their 50s while the coping cohort contained the largest proportion of 371 people in their 70s. members of this group who had been diagnosed $\geq 10$ years ago all reported co-morbidities

374 (arthritis, hypertension, diverticulitis) during interview, while all three who had been 375 diagnosed $\leq 3$ years ago did not. In contrast, the other cohorts were relatively similar in terms 376 of mean time since COPD diagnosis, with the longest diagnosed group (contrary) most likely 377 to 'explain' their condition during interview relative to the aging process. While to some 378 extent these findings diverge from Frank's (1995) suggestion that the restitution narrative is 379 more frequently expressed by those for whom illness is more recently diagnosed, the known 380 lack of a 'cure', the tendency for COPD diagnosis to occur at a relatively advanced age, and 381 the frequently gradual and imperceptible progression of the disease may help explain this pattern. In part they speak to Yoshida’s (1993) pendulum model of identity re-construction. While not predictive, age and gender certainly seemed to contour the narratives people 384 provided.

Further distinctions were identified in the relationships between narrative presented and education, occupation and affluence. First, the coping and contrary groups had, on 387 average, left continuous education a year later than the chaos and challenge groups. However, 
a notable distinction between the latter two was that everyone in the chaos cohort had subsequently studied for additional qualifications, including undergraduate and postgraduate degrees. Second, in line with the above, the chaos group were least likely to (have) work(ed)

391 in manual occupations. Reflecting their sense of transience, the chaos group was most likely 392 to describe themselves as currently unable to work, a manifestation perhaps of how tangibly 393 illness had affected them. Despite their relative ages, but consistent with their narratives, the coping and contrary cohorts were most likely currently to be in paid employment. The challenge cohort was most likely to be retired. Third, while the highest household incomes were, unsurprisingly, reported by the working cohorts (although, tellingly, two of the chaos 397 group were unable to estimate their income), in a more holistic assessment of relative 398 deprivation indicators (income, housing, employment, education, etc.) the chaos group came 399 from the most 'well off' neighbourhoods. The coping group lived in the most deprived areas. 400 Although no cohort was particularly wealthy, data partly support Williams' (2000) hypothesis 401 that biographical disruption may be most severe amongst the higher socio-economic classes 402 due in part to their higher expectations for life and the less frequent prior experience of 403 adversity. deprivation is particularly important. Specifically, data for the challenge group depicted fairly linear life trajectories, having left school relatively early, worked in manual occupations, and

407 retired with relatively little accumulation of wealth. Conversely the chaos group, whilst 408 having left education relatively early acquired subsequent qualifications, experienced 409 occupational mobility (in the sense of moving to non-manual occupations) and relative 410 economic security (hence reporting the least deprivation). It was against this background that 411 the disruption of illness was experienced as particularly acute and that the most 'hard 412 working' illness narratives were produced (Jordens et al. 2001: 1235). 


\section{$414 \quad$ Physical and behavioural measures}

415

417

419

420

421

422

425

426

427

428

429

430

431

432

433

434 435

Patterns linking patient narratives, physical and behavioural measures and thus aspects of the embodied experience were similarly observable. The chaos group had the lowest leg strength and hand grip scores but the least severe airflow obstruction. While most had relatively minor and simplistic COPD-related medication regimes (i.e. mainly reliant on inhalers) half reported co-morbidities.

The coping group, whose measures placed them somewhere near the middle of the spectrum of upper body and lower body strength test results, had worse walking performance (ISWT), participated in the lowest light to vigorous physical activity and lowest time sedentary (assessed via an accelerometer over 7 days), which perhaps reflected the philosophy of being active at their 'own pace'. They also had the poorest lung function, were the most likely to report co-morbidities, and reported the most extensive COPD-related medication regimes. While the contrary group also tended to be in the middle range of physical measures (physical function and respiratory health) they returned the highest light to vigorous activity scores, and the lowest total time sedentary.

Finally, the challenge cohort had the highest leg strength scores and the second best grip strength, but presented a diverse pattern of lung function scores, scoring highest in two categories and second in two others. They were least likely to report co-morbidities. This cohort performed best in the ISWT (an indication of exercise capacity) yet they were also most likely to self-report walking to be 'hard' (evaluated through questionnaire data). This perception of difficulty was partly reflected in the accelerometer-assessed physical activity where they ranked second in terms of moderate to vigorous activity, and third in time spent 
undertaking light physical activity. They ranked second of the four groups in terms of daily sedentary time.

Thus patterns were evident between physiological measures and narrative expressed.

439 Supporting the development of aforementioned measures of health status (CAT) and

440 breathlessness (mMRC), lung function did not closely align with illness narratives. Physical

441 strength was, to some extent, better aligned to patients’ rejection or acceptance of identifying

442 as ill, with the most physically strong (challenge) expressing the intention to live with and

443 seek to abate the progression of COPD through physical activity, and the physically weakest

444 (coping) exhibiting resignation. Those who expressed the strongest sense of agency

445 (challenge and contrary) were, in turn, the most physically active while those who effectively

446 accepted an identity of illness (coping and chaos) were the least active. Additionally,

447 however, the existence of co-morbidities (plus, for the chaos cohort, other complicating

448 factors) promoted patients' acceptance of the medical categorisation of illness (i.e. chaos and 449 coping cohorts), whereas the most medically resistant narratives (i.e. the contrary and 450 challenge cohorts who did not perceive themselves to be ill or explicitly sought to combat

451 illness) were given by those who had a more 'one-dimensional' illness experience.

It is, of course, impossible to specify causation - whether activity levels were a cause or consequence of attitudinal and behavioural responses to COPD diagnosis - but combining

454 the challenge cohort's ISWT scores with perceptions of 'ease of walking', for example, 455 suggests an agreement between perception and physical test results. Indeed, it is reasonable to 456 suggest that the findings are influenced by a degree of double-bind (Elias 1987a) or indeed 457 'virtuous circle'; that is to say, multiple comorbidities align with poor lung function and 458 particular attitudes towards illness, and those with relatively good physical strength are able 459 to keep active, maintain strength, resist the onset of other conditions and vocalise a 460 concordant outlook. While the severity of disease (as medically assessed) did not determine 
461 social life, a 'dialectic interaction' existed between the biological and social (Timmermans and Haas 2008: 661).

What we can say with more certainty is that, while the chaos cohort was particularly strongly affected by social structural factors, the other three groups (expressing what Frank (1995) calls quest and restitution narratives) were seemingly more heavily influenced by physiological factors and thus embodied condition. The stronger influence of external factors on the chaos narrative is, moreover, logically consistent with the expression of a lack of control. Indeed, underpinning the presentation of the chaos narrative are demographic/life trajectory factors experienced as so overwhelming that they appear to disrupt the connections with embodied condition. For example, the incongruence between respiratory capacity and

471 relative physical strength amongst this group suggests that while they did not 'feel' it, 472 physically they had a relatively high capacity (i.e. lung function) to exert control over illness 473 and everyday life. In contrast, narratives characterised by a greater sense of agency or control, 474 are more strongly influenced by embodied or 'internal' factors. Specifically, the physical 475 performance of the challenge cohort was largely commensurate with the philosophies 476 depicted in their quest narratives (including participating in more physical activity). Of the 477 two groups presenting a variant of the restitution narrative, the coping cohort offered less 478 contestation (either in terms of their diagnosis or restorative actions), had worse lung function, 479 more extensive medical regimes, more frequently had co-morbidities, and were less active. 480 Conversely, the contrary group resisted the label of 'being ill', stated that they did not 481 perceive themselves to be restricted in daily living and demonstrated that such attitudes 482 matched behaviour assessed through empirical measures. Thus for these three cohorts, 483 activity measures and perceptions of illness aligned. 
While the above suggests that illness narratives are not free-floating but shaped by

487 both broader social structural factors and embodied experience, Elias's (1987a; 1987b)

488 approach alerts us to the idea that the 'reality congruence' of what people seek to portray

489 (indeed 'believe') in the ‘special situation' of interview (Atkinson 2009), relates to the blend

490 of involvement and detachment within an individual's thought processes which, in turn, is

491 influenced by elements of physical and social (in-)security. Consequently it is unsurprising

492 that the apparent compatibility between narrative and physical measures is greater amongst

493 those expressing a quest or restitution narrative than for the chaos cohort. Specifically, social

494 structural factors are particularly influential for the latter because, by definition, such

495 'external' factors are less amenable to individual agency and control. In other words, 496 ontologically insecure patients produce the 'most involved' accounts of illness. While 497 described in the literature as 'chaotic' (Frank 1995), or possessing a greater complexity in 498 combining multiple narrative genres (Jordens et al. 2001), placed in historical and cultural 499 context, we can understand them as effectively defying the kind of rationality and reflexivity that characterises more detached forms of thinking dominant in contemporary western 501 societies.

But equally an Eliasian sociology of knowledge enables us to make sense of apparently incongruous data. Because involvement and detachment is not a zero-sum game

504 (Kilminster 2004), people’s ability to 'impression manage' is as important as their ability to 505 verbalise a position that coheres with the behaviour we were able to measure. Within the 506 study 'inconsistent' findings, and thus potential indications of impression management, 507 occurred in relation to accounts of physical activity and smoking. First, in addition to the 508 incongruence between the chaos cohort's perceptions and measurements of strength and 509 respiratory health, it was notable that the coping cohort was most likely, via questionnaire, to 
510 report themselves as being 'sporty' in both their youth and adulthood and provide the highest

511 rating of 'current sportiness'. Conversely the most active group (contrary) rarely depicted

512 themselves as having a 'sporty' child- or adult-hood. Second, there were discrepancies

513 between how individuals reported their smoking biographies in interviews and questionnaires.

514 The greatest discrepancies between these two sets of findings occurred in relation to the

515 chaos cohort (a greater number of whom said in interview that they currently smoked), and

516 the coping and challenge cohorts (a greater number of whom said in interview that they had

517 never smoked). This would appear to support Jordens et al.'s (2001: 1235) conjecture that

518 'simple narratives may reflect the ... process of reinstating order by assigning meaning,

519 whilst complex narratives reveal the process happening “on line” as it were, in discourse'.

520

While partly this shows that defining one’s identity or self as 'sporty' or 'a smoker' is

521 somewhat subjective, it also suggests that what counts as 'true' at any one time is

522 contextually and temporally bounded. For instance, one could argue that the coping cohort's

523 acknowledgement of their physical limitations (getting by, at their 'own pace') behove them

524 to present a moral narrative including a history of being physically active and not smoking.

525 Conversely the underlying illness 'denial' of the contrary group effectively absolved them

526 from an obligation to maintain self-worth via a 'virtuous' history of physical activity or to

527 vary their representation of smoking behaviour between interview and the relatively

528 impersonal context of questionnaire survey. Denying the existence of illness behoves them to

529 deny the aetiological importance of both exercise and smoking. It is also logically consistent

530 to think the challenge group, whose meta-narrative was essentially one of currently

531 undertaking morally responsible action, would gain comfort from depicting more socially

532 acceptable smoking behaviour in interview. Finally, the chaos cohort who, as illustrated,

533 struggled to control their condition, perhaps equally struggled to control their self-

534 representation in the interview setting and thus presented as less morally virtuous compared 
535 to their questionnaire responses. Because they did not perceive themselves as relatively 536 physically capable, in 'reality testing' (Elias 1987a) of accelerometer measurement, they

537 performed much 'worse' than predicted in light of their performance in the 'special occasion' 538 of clinical testing.

539 What we see therefore is that while narratives, social structure and embodied 540 experience interconnect, our reading of 'truth' must be sensitive to the social positioning of

541 the 'teller' and the specific content relayed. While the previous section identified that people

542 are not all equally capable of presenting narrative accounts which are (relatively) congruent

543 with their embodied experience, here we see that people present narrative accounts which

544 contain varying elements of what others would observe, what the tellers themselves 'believe',

545 and what they would like others to believe about them. Because physical activity and

546 smoking were the biographical aspects that most directly resonated with notions of blame and

547 self-worth (Bury 2001), they were also the aspects of narrative that hold the most significant

548 social and emotional consequences for the teller. As Elias (1987a) indicates, where

549 knowledge is invested with the greatest degree of immediate self-interest, it is most likely to 550 be infused with 'fantasy laden' or emotionally comforting thinking. Moral rather than 551 contingent narratives are therefore most likely to be reflexively presented in the interview 552 setting.

553

\section{Conclusion}

Building on previous studies (Lindqvist and Halberg 2010), this article demonstrates 556 how COPD patients may depict their illness experience through a particular set of narratives.

557 Moreover, while there are certain condition-specific elements to the narratives expressed, 
558 there are also more generic patterns in terms of contingent, moral and core subthemes (Bury 559 2001), as well as resonance with chaos, quest and restitution narratives (Frank 1995).

560 But perhaps more significantly this paper uses Elias first to speak to key debates about 561 the use of illness narrative, and second to effectively reconceptualise central issues. Thus we 562 see that demographic categories such as gender and age, and timing of diagnosis may 563 influence the illness experience, as might cultural contingencies of biographical trajectory, 564 such as experiences of social mobility and relative affluence (relative, that is, across one's 565 life-course). Similarly the data suggest a pattern linking the kinds of narrative expressed and 566 physical measures of the embodied condition. Physical function, respiratory health and 567 physical activity patterns influenced the way those diagnosed with COPD experienced this 568 particular illness. Qualitative illness narratives appear, therefore, largely 'authentic', and 569 correlate with the kind of quantified physiological health outcomes that form the basis of 570 biomedical knowledge and vice versa. Illness narratives are not free-floating but shaped by 571 both broader social structural factors and embodied experience. Calls for the development of 572 a sociology of disease therefore seem well-founded (Timmermans and Haas 2008).

574 whether narratives can be treated as testimony rather than perspective, but what are the social 575 contingencies we must consider when seeking to assess the 'reality congruence' of (particular 576 parts of) patients' accounts. Specifically we identify the significance of both moral and core 577 narratives, for the former holds particular resonance for the ontological security, social and 578 emotional wellbeing of interviewees, while the latter provides an indication of the 579 individual's capacity for relative detachment. Those who express the least 'control' of their 580 illness are similarly likely to be least in 'control' of what they convey in interview about their 581 response to illness, while those who project accounts which could be said to be more 582 consistent with cultural expectations and dominant illness moralities, are most likely to be 
583 able to present accounts which: a) they would like others to see as 'true'; thus b) vary most

584 from the lived experience; and subsequently c) a researcher is likely to believe because it is 585 delivered with the appearance of reflexivity and rationality which humans have come to see 586 as reliable tools for assessing the value of knowledge.

587 Fundamentally then, narratives are of considerable analytic value, both for social 588 scientists of medicine exploring the lived illness experience, but also biomedical scientists 589 and practitioners seeking to invoke lifestyle changes in patients. This paper suggests that the 590 insights of both quantitative and qualitative data can be enhanced by a critical cross591 referencing and thus the advantages of mixed-method and multidisciplinary working over 592 epistemological isolation.

\section{References}

594 Atkinson, P., 2009. Illness narratives revisited: the failure of narrative reductionism. Sociological Research Online 14 (5), http://www.socresonline.org.uk/14/5/16.html

596 Bailey, P., 2001. Death stories: acute exacerbations of chronic obstructive pulmonary disease. 597 Qualitative Health Research 11 (3), 322-38.

598 Bailey, P., 2004. The dyspnea-anxiety-dyspnea cycle - COPD patients’ stories of 599 breathlessness: “It’s scary when you can’t breathe”. Qualitative Health Research 14 $600 \quad$ (6), $760-78$.

601 Bestall, J., Paul, E., Garrod, R., et al 1999. Usefulness of the Medical Research Council 602 (MRC) dyspnoea scale as a measure of disability in patients with chronic obstructive 603 pulmonary disease. Thorax 54, 581-586. 
604 Boeckxstaens, P., Deregt, M., Vandesype, P., Willems, S., Brusselle, G., De Sutter, A., 2012. 605 Chronic obstructive pulmonary disease and comorbidities through the eyes of the 606 patient. Chronic Respiratory Disease 9 (3), 183-91.

607 Bury, M., 1982. Chronic illness as biographical disruption. Sociol Health Illn. 4, 2, 167-82.

608 Bury, M., 2001. Illness narratives: fact or fiction. Sociol Health Illn. 23(3): 263-85.

609 Edwards, R., Young, A., Hosking, G., Jones, D. 1977. Human Skeletal Muscle Function:

610 Description of Tests and Normal Values. Clinical Science and Molecular Medicine 52

611 (3), 283-90

612 Elias, N. (2000) The Civilizing Process: Sociogenetic and Psychogenetic Investigations. Blackwell: Oxford

614 Elias, N., 1987a. Involvement and Detachment. Blackwell, Oxford.

615 Elias, N., 1987b. On human beings and their emotions: a process-sociological essay. Theory, Culture and Society 4, 339-61.

617 Faulkner, A., McNamee, M., Coveney, C., Gabe, J. 2017. Where biomedicalisation and magic meet: Therapeutic interventions of elite sports injury in British professional football and cycling. Soc Sci Med, 178, 136-143

620 Frank, A., 1995 The Wounded Storyteller: Body, Illness and Ethics. University of Chicago 621 Press, Chicago.

622 Hansen, E., Walters, J., Wood Baker, R., 2007 Explaining chronic obstructive pulmonary 623 disease (COPD): perceptions of the role played by smoking. Sociol Health Illn. 29 (5), 624 730-49. 
625 Jones, P., Harding, G., Berry, P., Wiklund, I., Chen, W-H., Kline Leidy, N. 2009. Development and first validation of the COPD Assessment Test. Eur Respir J 34, 648-654.

628

Jordens, C., Little, M., Paul, K., Sayers, E-J 2001. Life disruption and generic complexity: a social linguistic analysis of narratives of cancer illness. Soc Sci Med, 53, 1227-1236.

630

631

632

633

634

635

636

637

638

639

640

641

642

643

644

645

646

Kilminster, R., 2004. From distance to detachment: knowledge and self-knowledge in Elias’s theory of involvement and detachment. In Loyal, S., Quilley, S. (Eds.), The sociology of Norbert Elias Cambridge University Press, Cambridge.

Lindqvist, G., Hallberg, L. 2010. 'Feelings of guilt due to self-inflicted disease’: a grounded theory of suffering from chronic obstructive pulmonary disease (COPD). Journal of Health Psychology 15 (3), 456-466.

Nicholson, P., Anderson, P., 2003. Quality of life, distress and self-esteem: a focus group study of people with chronic bronchitis. British Journal of Health Psychology 8, 25170.

Orme, M., Esliger, D., Kingsnorth, A., Steiner, M., Singh, S., Malcolm, D., Morgan, M., Sherar, L. 2016. Physical activity and respiratory health (PhARaoH): data from a cross-sectional study. Open Health Data 4: e4, DOI: http://dx.doi.org/10.5334/ohd.28

Parvatikar, V., Mukkannavar, P. 2009. Comparative study of grip strength in different positions of shoulder and elbow with wrist in neutral and extension positions. Journal of Exercise Science and Physiotherapy 5 (2), 67-75.

Pitta, F., Troosters, T., Spruit, M., Probst, V., Decramer, M., Gosselink, R., 2005. Characteristics of physical activities in daily life in chronic obstructive pulmonary disease. American Journal of Respiratory Critical Care Medicine 171, 972-77. 
648 Polkey, M. Moxham, J. 2006. Attacking the disease spiral in chronic obstructive pulmonary disease. Clin Med 6 (2), 190-6.

650 Quanjer, P., Tammeling, G., Cotes, J., Pedersen, O., Peslin, R., Yernault, J-C. 1993. Lung volumes and forced ventilator flows. Eur Respir J 6 (16), 5-40.

652 Riessman, C., 2002. Illness narratives: positioned identities. Invited annual lecture, Cardiff

653

654

655

656

657

658

659

660

661

662

663

664

665

666

667

668

669 University. https://www.researchgate.net/profile/Catherine_Riessman/publication/241501264_Illn ess_Narratives_Positioned_Identities/links/54fa2bf10cf23e66f03116eb.pdf

Singh, S., Morgan, M., Scott, S., Walters, D., Hardman, A., 1992. Development of a shuttle walking test of disability in patients with chronic airways obstruction. Thorax 47, 1019-1024.

Timmermans, S., Haas, S. 2008. Towards a sociology of disease. Sociol Health Illn 30 (5), 659-676.

Thomas, C., 2010. Negotiating the contested terrain of narrative methods in illness contexts. Sociol Health Illn. 32 (4), 647-660.

Van Kreiken, R., 1998. Norbert Elias. Routledge, London.

Vestbo, J., Anderson, W., Coxson, H., Crim, C., Dawber, F., Edwards, L., Hagan, G., Knobil, K., Lomas, D., MacNee, W., Silverman, E. Tal-Singer, R. 2008. Evaluation of COPD Longitudinally to Identify Predictive Surrogate End-points (ECLIPSE). Eu Resp Jo, 31, 869-873.

Williams, J., 2011. The challenge of increasing uptake of pulmonary rehabilitation: what can we do to maximise the chances of success? Chronic Respiratory Disease 8 (2), 87-88. 
670 Williams, S.J., 2000 Chronic illness as biographical disruption or biographical disruption as

672 Williams, V., Bruton, A., Ellis-Hill, C., McPherson, K., 2007. What really matters to patients 673 living with chronic obstructive pulmonary disease? An exploratory study. Chronic Respiratory Disease, 4, 77-85.

675 Williams, V., Bruton, A., Ellis-Hill, C., McPherson, K., 2011. The importance of movement for people living with chronic obstructive pulmonary disease. Qualitative Health Research, 21 (9), 1239-48.

678

Wilterdink, N.A. 2003. Norbert Elias’s sociology of knowledge and its significance for the study of the sciences. In: Dunning, E., Mennell, S. (Eds.), Norbert Elias: Sage masters

680 in modern social thought, Volume 1. Sage, London.

681 Yoshida, K. 1993. Reshaping of self: a pendular reconstruction of self and identity among 682 adults with traumatic spinal cord injury. Sociol Health Illn, 15 (2), 217-245.

Table 1: Illness Narratives and Quantitative

Measures

\begin{tabular}{|c|c|c|c|c|}
\hline & \multicolumn{4}{|c|}{ Narrative } \\
\hline & $\begin{array}{l}\text { Chaos } \\
(n=6)\end{array}$ & $\begin{array}{l}\text { Challenge } \\
\quad(n=5)\end{array}$ & $\begin{array}{c}\text { Contrary } \\
(n=8)\end{array}$ & $\begin{array}{c}\text { Coping } \\
(n=7)\end{array}$ \\
\hline \multicolumn{5}{|l|}{ Demographics } \\
\hline Gender (male : female) & $3: 3$ & $3: 2$ & $6: 2$ & $6: 1$ \\
\hline Age (years) & 62.1 & 62.6 & 64.5 & 68.5 \\
\hline Years since COPD diagnosis & 6.8 & 15.8 & 16.3 & 13.8 \\
\hline Age left full-time education (years) & 15.3 & 15.2 & 16.0 & 16.5 \\
\hline Manual occupation ( $\mathrm{n}=$ described in interview) & 3 & 3 & 6 & 4 \\
\hline IMD score & 32.9 & 20.2 & 21.9 & 13.9 \\
\hline Comorbidities reported ( $\mathrm{n}=$ reported in interview) & 3 & 1 & 3 & 6 \\
\hline \multicolumn{5}{|l|}{ Respiratory health } \\
\hline Interview smoking status (current : former : never) & $5: 1: 0$ & $1: 1: 3$ & $2: 5: 1$ & $0: 4: 3$ \\
\hline $\begin{array}{l}\text { Questionnaire smoking status (current : former : } \\
\text { never) }\end{array}$ & $2: 4: 0$ & $3: 2: 0$ & $1: 6: 1$ & $1: 5: 1$ \\
\hline
\end{tabular}




\begin{tabular}{lcccc} 
FEV1 (L) & 2.06 & 2.4 & 1.89 & 1.15 \\
FEV1\%pred & 76.8 & 72.4 & 65.5 & 41.7 \\
FVC (L) & 3.5 & 3.8 & 3.7 & 3.18 \\
FEV/FVC & 58.7 & 53.6 & 52.8 & 37.4 \\
\hline Physical activity & & & & \\
Sedentary time (minutes/day) & 616 & 595 & 547 & 678 \\
Light PA (minutes/day) & 336 & 348 & 368 & 326 \\
MVPA (minutes/day) & 13 & 16.1 & 16.4 & 9.1 \\
Sporty as a child (n = yes) & 3 & 2 & 1 & 5 \\
Sporty during adulthood (n = yes) & 1 & 2 & 1 & 5 \\
Sportiness scale (0-100) & 10 & 34 & 40 & 51 \\
\hline Physical function & & & & \\
Leg strength (kg) & 32.7 & 49.8 & 36.1 & 35.8 \\
Grip strength (kg) & 33.17 & 39.5 & 39.7 & 37.3 \\
ISWT (m) & 308 & 458 & 395 & 276 \\
\hline
\end{tabular}

685 Abbreviations: COPD, chronic obstructive pulmonary disease; FEV1, forced expiratory 686 volume in one second; FVC, forced vital capacity; IMD, index of multiple deprivation; ISWT; 687 incremental shuttle walk test; MVPA, moderate-to-vigorous physical activity; PA, physical 688 activity (see Singh et al. 1992; Edwards et al. 1977; Parvatikar et al. 2009; and Quanjer et al. 6891993 for details of measurement protocols).

690 All figures refer to cohort means unless otherwise stated. 